\title{
Tablet for Suspension Dosage Form
}

National Cancer Institute

\section{Source}

National Cancer Institute. Tablet for Suspension Dosage Form. NCI Thesaurus. Code C61005.

A tablet that changes into a suspension when added to a liquid solution. 